\title{
Editorial
}

\section{Recent Advances in Multiphase Flows in Engineering}

\author{
Muhammad Mubashir Bhatti $\mathbb{D}^{1},{ }^{1}$ Marin Marin $\mathbb{D}^{2},{ }^{2}$ and Ahmad Zeeshan $\mathbb{D}^{3}$ \\ ${ }^{1}$ College of Mathematics and Systems Science, Shandong University of Science and Technology, Qingdao 266590, \\ Shandong, China \\ ${ }^{2}$ Department of Mathematics and Computer Science, Transilvania University of Brasov, Brasov 500093, Romania \\ ${ }^{3}$ Department of Mathematics and Statistics, FBAS, International Islamic University, Islamabad 44000, Pakistan \\ Correspondence should be addressed to Muhammad Mubashir Bhatti; muhammad09@shu.edu.cn
}

Received 28 July 2021; Accepted 28 July 2021; Published 1 September 2021

Copyright (c) 2021 Muhammad Mubashir Bhatti et al. This is an open access article distributed under the Creative Commons Attribution License, which permits unrestricted use, distribution, and reproduction in any medium, provided the original work is properly cited.

\section{Introduction}

Multiphase phase flows include the flow of matter in two or more than two thermodynamic phases and involve solid-gas flows, bubbly flows, and sprays. They pervaded practically every feature of human life, and enhanced comprehension of multiphase flows can play a significant role in ensuring three essential requirements of humans, for instance, sustainable food production, clean water, and clean air. The understanding of multiphase flows is beneficial to examine the key mechanisms of the natural environment and in man-made systems. Multiphase flows have numerous applications in nanotechnology, chemical process, energy, environmentally sustainable technologies, critical infrastructures, and biological and healthcare applications, i.e., pharmaceuticals, manufacturing processes, and design materials. Table 1 shows the various classifications of multiphase flows. The examples given in the table are intended only to show the reader an overview of the applications and different types of multiphase flows that appear in various biological, industrial, and diverse natural systems.

Considering the importance of multiphase flows in engineering, this Special Issue was introduced. In total, 17 papers were submitted to this Special Issue, and out of them, 12 were selected for publication.

\section{Recent Advances in Multiphase Flows in Engineering}

Alqahtani et al. [1] discussed the heat and mass transfer process through a wedge. The applications of the problems mainly occur in civil engineering. The effects of magnetic field and cross-diffusion gradients are also taken into consideration. According to their results, they found that the Prandtl number diminishes the temperature profile. However, mass transport increases due to higher values of Soret number and the converse effects shown for Schmidt number.

Rashid et al. [2] studied gold nanoparticles suspended in the water-based nanofluid under heat transfer effects. They contemplated various forms of nanoparticles, including lamina, hexahedron, column, sphere, and tetrahedron. The mathematical formulation is performed via similarity transformations, and the homotopy analysis method was used to determine the solutions. According to the results, it is found that heat transfer is maximum for the lamina shape nanoparticles and the sphere shape nanoparticles show a considerable behavior in temperature profile as compared to other types of nanoparticles.

Chu et al. [3] studied the cross-flow in the streamwise direction towards a moving surface under viscous dissipation and magnetic effects. They further determined the stability analysis and presented dual solutions. They found that the velocities in the direction of streamwise in addition to cross-flow reduces in the upper branch solution; at the same time, a converse impact is observed for the lower branch solution. Furthermore, the impact of suction on the velocities uplifts the solutions in the upper branch and diminishes the solutions in the lower branch.

Han et al. [4] used the CFD-DEM coupling technique to set up the simulation model of two-phase flow through a drill pipe. They determined the impact of cutting removal on air velocity, the mass flow rate of cutting on the flow properties, the cutting removal impact, and the pressure 
TABLE 1: Classification of multiphase flows.

\begin{tabular}{|c|c|c|c|c|c|}
\hline & Gas-solid flows & Liquid-solid flows & Gas-liquid flows & Liquid-liquid flows & $\begin{array}{l}\text { Gas-solid } \\
\text { flows }\end{array}$ \\
\hline Natural & $\begin{array}{l}\text { Sand storms, } \\
\text { volcanoes, and } \\
\text { avalanches }\end{array}$ & $\begin{array}{l}\text { Sediment transport of sand in } \\
\text { rivers and sea, soil erosion, } \\
\text { mud slides, debris flows, and } \\
\text { iceberg formation }\end{array}$ & $\begin{array}{l}\text { Rain droplets, ocean waves, } \\
\text { and mist formation }\end{array}$ & - & - \\
\hline Biological & $\begin{array}{c}\text { Aerosols (dust } \\
\text { particles) and smoke } \\
\text { (fine soot particles) }\end{array}$ & Blood flow & Aerosols (liquid droplets) & - & - \\
\hline Industrial & $\begin{array}{c}\text { Pneumatic } \\
\text { conveyers, dust } \\
\text { collectors, fluidized } \\
\text { beds, and solid } \\
\text { propellant } \\
\text { Rockets, pulverized } \\
\text { solid particles, spray } \\
\text { drying, and spray } \\
\text { casting }\end{array}$ & $\begin{array}{l}\text { Slurry transportation, } \\
\text { flotation, fluidized beds, } \\
\text { water jet cutting, and sewage } \\
\text { treatment plants }\end{array}$ & $\begin{array}{l}\text { Boiling water and pressurized } \\
\text { water nuclear reactors, } \\
\text { chemical reactor desalination } \\
\text { systems, boilers, heat } \\
\text { exchangers, internal } \\
\text { combustion engines, liquid } \\
\text { propellant rockets, and fire } \\
\text { sprinkler suppression systems }\end{array}$ & $\begin{array}{l}\text { Emulsifiers, fuel-cell } \\
\text { systems, microchannel } \\
\text { applications, and } \\
\text { extraction systems }\end{array}$ & $\begin{array}{l}\text { Air lift } \\
\text { pumps and } \\
\text { fluidized } \\
\text { beds }\end{array}$ \\
\hline
\end{tabular}

drop of cutting-gas-two-phase flow. According to their analysis, they found that the drag force of drilling cuttings becomes higher with an increment in air velocity. When the mass flow rate of cutting is constant, it enhances the air velocity for cutting removal and tends to enhance the pressure drop in the inner hole of the drill pipe. On the contrary, when the air velocity of cutting removal is constant, then the mass flow rate of cutting and the pressure drop in the inner hole of the drill pipe rises.

Gonzalez-Trejo et al. [5] studied fluid dynamics within a pair of submerged entry nozzle models with a square crosssection bore. They contemplated water as a working fluid with the Froude similarity criterion. The proposed model comprises a square-shaped tube having one inlet and two lateral squared exits at the bottom; however, the model does not have exit ports. The proposed turbulence model is presented as a large eddy simulation having dynamics $k$ equation filtering. According to the results, it is found that with one large vortex, the flow pattern within the pool nozzle can be defined, whereas, in the nozzle without the pool, the flow pattern depicts a complex mechanism distinguished by two small vortexes.

Yousaf et al. [6] presented a novel method known as the cubic trigonometric B-spline technique based on the Hermite formula. They used this method to solve the convection-diffusion equation. They found that the main benefit of this scheme is that the approximate solution is obtained as a smooth piecewise continuous function, which enables us to determine the approximate solution at any point in the location with higher accuracy.

Basit et al. [7] examined heat transfer with forced convection from arrays of prolate particles is formulated by employing the second-order immersed boundary Lattice Boltzmann technique. They found that Reynolds number and solid volume fraction significantly enhanced the Nusselt number and Hermans orientation factor. Furthermore, they noticed that the impact of orientation on Nusselt number is remarkable.
Irfan et al. [8] examined the theoretical impact of magnetized stagnation point flow on heat and mass transfer towards a shrinking and stretching porous surface. Furthermore, they elaborated the behavior of chemical reaction, thermal radiation, swimming of gyrotactic microorganisms, and heat source/sink. MATLAB software has been used to examine the solutions using the bvp $4 c$ command. They concluded that the skin friction coefficient increases due to an increment in porosity and magnetic parameters. Moreover, they discussed that the Peclet number and Lewis number enhanced the motile microorganism profile.

Arain et al. [9] studied bioconvection flow with nanoparticles under the presence of an induced magnetic field. They have contemplated Carreau fluid which is moving between a pair of rotating circular plates. Furthermore, they used the DTM-Pade approximation to determine the numerical solutions. They also discussed the effects of shearthinning, shear-thickening, and Newtonian fluid models as a special case of the proposed study.

Song et al. [10] presented a design and implementation of the array logging tool for horizontal production logging. The proposed project has designed a staggered probe array flow meter well logging apparatus based on the characteristic of electromagnetic wave specific retention meter that can fully cover the wellbore fluid and improve the flow measurement accuracy. According to the application in horizontal wells, the accuracy of this measuring instrument has been proved to be more than $90 \%$. It can meet the requirements of production logging interpretation in horizontal wells.

Farooq et al. [11] employed a simplified finite difference technique to examine the nanofluid mechanism through an exponentially stretching surface under the effects of thermal radiation. They discussed the efficiency of the proposed scheme by comparing the results with other similar methods. Their outcomes found that the Eckert number enhanced the velocity profile; however, the thermal Grashof number opposes the temperature profile. 
Riaz et al. [12] discussed the entropy mechanism of a three-dimensional wavy flow using Eyring-Powell nanofluid. Mathematical and physical modeling is performed based on the lubrication approach. Furthermore, they used the homotopy perturbation approach to solve the coupled nonlinear differential equations. They showed that entropy generation reduces due to concentration parameters but upsurges due to viscous dissipation. Moreover, it is presented that Eyring-Powell depicts the difference in behavior in the entropy generation and the presence of nanoparticles due to the significant dissipation effects. In addition, it travels faster than the viscous fluid. This study may be helpful for cancer therapy in biomedicine by nanofluid properties in multiple drugs contemplated as a non-Newtonian fluid.

\section{Conflicts of Interest}

The editors declare that there are no conflicts of interest.

Muhammad Mubashir Bhatti
Marin Marin
Ahmad Zeeshan

\section{References}

[1] A. M. Alqahtani, U. Khan, N. Ahmed, S. T. Mohyud-Din, and I. Khan, "Numerical investigation of heat and mass transport in the flow over a magnetized wedge by incorporating the effects of cross-diffusion gradients: applications in multiple engineering systems," Mathematical Problems in Engineering, vol. 2020, Article ID 2475831, 10 pages, 2020.

[2] U. Rashid, T. Abdeljawad, H. Liang, A. Iqbal, M. Abbas, and M. Siddiqui, "The shape effect of gold nanoparticles on squeezing nanofluid flow and heat transfer between parallel plates," Mathematical Problems in Engineering, vol. 2020, Article ID 9584854, 12 pages, 2020.

[3] Y. M. Chu, U. Khan, A. Zaib, and S. H. Shah, "Numerical and computer simulations of cross-flow in the streamwise direction through a moving surface comprising the significant impacts of viscous dissipation and magnetic fields: stability analysis and dual solutions," Mathematical Problems in Engineering, vol. 2020, Article ID 8542396, 2020.

[4] X. Han, P. Li, and J. Li, "CFD-DEM simulation of reverse circulation pneumatic cuttings removal during coal seam drilling," Mathematical Problems in Engineering, vol. 2020, Article ID 3707864, 2020.

[5] J. Gonzalez-Trejo, C. A. Real-Ramirez, I. Carvajal-Mariscal et al., "Hydrodynamic analysis of the flow inside the submerged entry nozzle," Mathematical Problems in Engineering, vol. 2020, Article ID 6267472, 14 pages, 2020.

[6] A. Yousaf, T. Abdeljawad, M. Yaseen, and M. Abbas, "Novel cubic trigonometric B-spline approach based on the Hermite formula for solving the convection-diffusion equation," Mathematical Problems in Engineering, vol. 2020, Article ID 8908964, 17 pages, 2020.

[7] R. Basit, X. Li, Z. Huang, and Q. Zhou, "Heat transfer studies of arrays of prolate particles in gas-solid flows," Mathematical Problems in Engineering, vol. 2020, Article ID 6639172, 12 pages, 2020.

[8] M. Irfan, M. A. Farooq, A. Mushtaq, and Z. H. Shamsi, "Unsteady MHD bionanofluid flow in a porous medium with thermal radiation near a stretching/shrinking sheet," Mathematical Problems in Engineering, vol. 2020, Article ID 8822999, 14 pages, 2020.

[9] M. B. Arain, M. M. Bhatti, A. Zeeshan, T. Saeed, and A. Hobiny, "Analysis of Arrhenius kinetics on multiphase flow between a pair of rotating circular plates," Mathematical Problems in Engineering, vol. 2020, Article ID 2749105, 17 pages, 2020.

[10] W. Song, H. Chen, Q. Zhang, and J. Zhang, "Design and implementation of the array logging tool on horizontal production logging," Mathematical Problems in Engineering, Article ID 6903970, 7 pages, 2020.

[11] M. A. Farooq, A. Salahuddin, A. Mushtaq, and M. Razzaq, "A simplified finite difference method (SFDM) solution via tridiagonal matrix algorithm for MHD radiating nanofluid flow over a slippery sheet submerged in a permeable medium," Mathematical Problems in Engineering, vol. 2021, Article ID 6628009, 17 pages, 2021.

[12] A. Riaz, A. Zeeshan, and M. M. Bhatti, "Entropy analysis on a three-dimensional wavy flow of eyring-powell nanofluid: a comparative study," Mathematical Problems in Engineering, vol. 2021, Article ID 6672158, 14 pages, 2021. 